In der Rubrik „Literatur kompakt" werden die wichtigsten Originalarbeiten aus der internationalen Fachliteratur referiert.

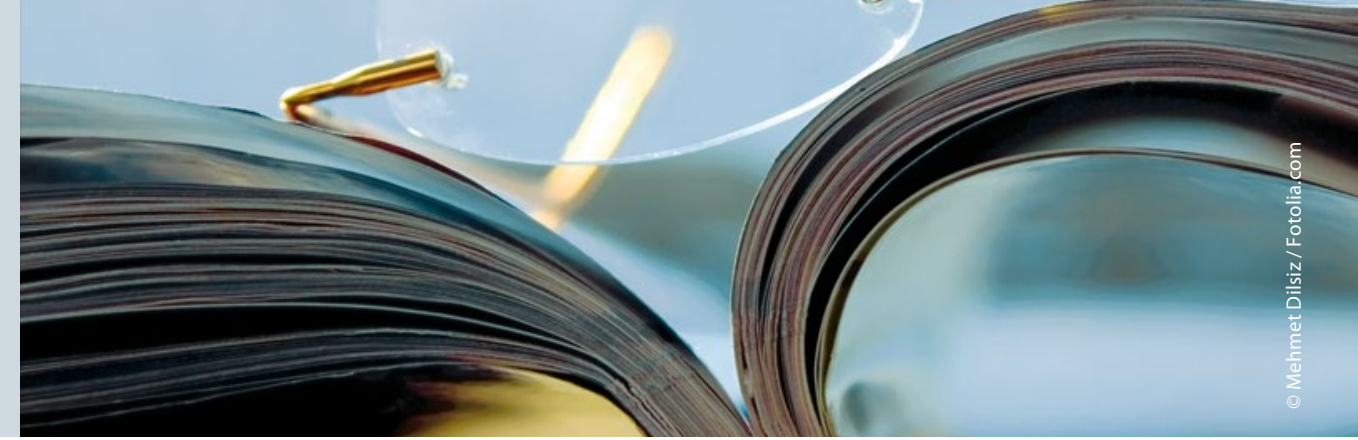

\title{
ASS nach Schlaganfall: In der Frühphase besonders gut wirksam
}

\begin{abstract}
In den ersten Stunden und Wochen nach einem zerebralen ischämischen Ereignis sind Rezidive besonders häufig. Die beste Vorbeugung ist der möglichst baldige Therapiebeginn mit ASS.
\end{abstract}

$\mathrm{D}$ ie Autoren fanden zwölf randomisierte Studien, in denen der weitere Verlauf von 15.778 Patienten nach einer kurzfristigen ischämischen Attacke (TIA) oder einem Schlaganfall mit und ohne ASS untersucht wurde. Die Häufigkeit von Rezidiven wurde in den ersten Wochen nach dem akuten Ereignis untersucht.

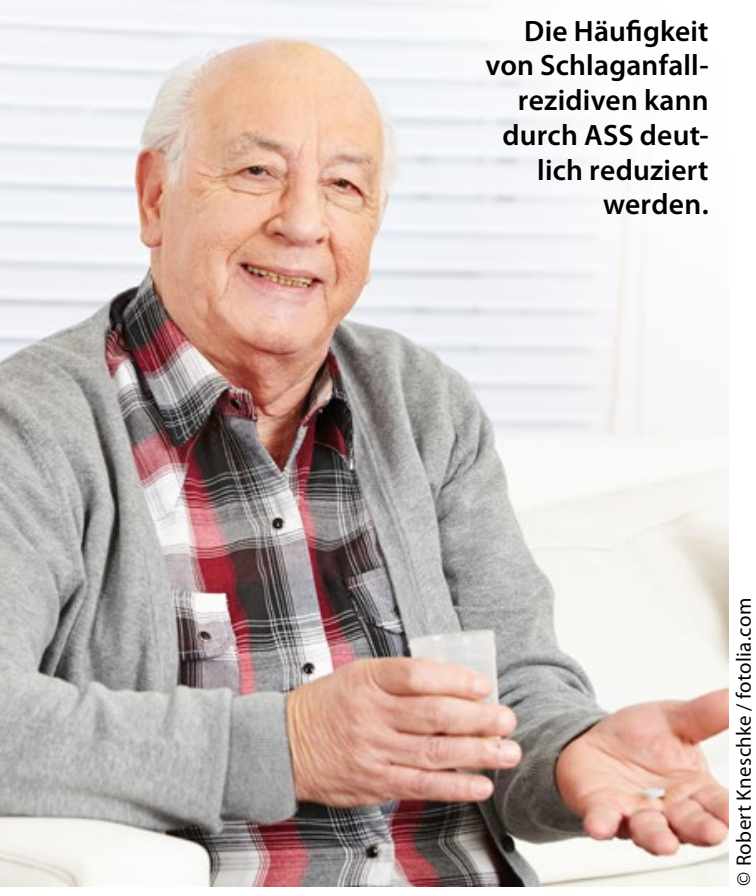

Besonders erfolgreich war die Prophylaxe mit ASS in der Frühphase. In den ersten zwei Wochen ging Zahl der Rezidive um $93 \%$, in den ersten sechs Wochen insgesamt um $60 \%$, schwere und tödliche Rezidive um $70 \%$ zurück. Schon zwischen der sechsten und zwölften Woche war ASS nur noch gering wirksam, jenseits der zwölften Woche war kein positiver Effekt mehr erkennbar.

Die Kombination von ASS mit Dipyridamol verhinderte nur jenseits der zwölften Woche Rezidive um 24\%, war im Übrigen aber nicht stärker wirksam als ASS allein. In einer Analyse von drei Studien mit 45.531 Patienten mit schweren Schlaganfällen wurde der größte Rückgang von Schlaganfällen nach zwei Wochen gemessen, wobei die Wirkung schon nach zwei bis drei Tagen einsetzte.

Rothwell PM et al. Effects of aspirin on risk and severity of early recurrent stroke after transient ischaemic attack and ischaemic stroke: timecourse analysis of randomised trials. Lancet. 2016;388:365-375

\section{Kommentar}

Es ist allgemein akzeptiert, dass in den ersten Tagen und Wochen nach einem Herzinfarkt oder Schlaganfall die Rezidivgefahr besonders hoch ist und im weiteren Verlauf geringer wird. Trotzdem sind Studien zur Sekundärprävention mit ASS in der Frühphase von transitorischen Attacken und
Schlaganfällen Mangelware. Die vorliegende Studie hat deshalb den Zeitverlauf der ASS-Wirkung auf Rezidive nach akuten ischämischen Ereignissen überprüft: Die Wirkung setzt bereits nach zwei bis drei Tagen ein, erreicht ihr Maximum nach zwei Wochen, ist zwischen der sechsten und zwölften Woche ausgeprägt und schwächt sich nach der zwölften Woche deutlich ab. Daraus leiten die Autoren praktisch bedeutsame, teils weitreichende Konsequenzen ab: 1. Die Leitlinien zur antithrombotischen Therapie nach Schlaganfall unterscheiden häufig nicht zwischen Früh- und Spätphase sowie zwischen ASS und Clopidogrel. In der Frühphase sollte ASS verordnet werden.

2. Schon beim ersten Arztkontakt sollten Patienten mit TIA und Schlaganfall ASS einnehmen und nicht etwa nur mit einer Verordnung entlassen werden.

3. Wenn Patienten mit Verdacht auf eine zerebrale Ischämie den Hausarzt oder Beratungsstellen anrufen, sollten sie nicht nur zum sofortigen Arztbesuch, sondern auch zur Einnahme von ASS aufgefordert werden.

4. Auch das paramedizinische Personal sollte beim ersten Patientenkontakt und entsprechendem Verdacht auf die ASS-Einnahme drängen.

5. Die Öffentlichkeit sollte über die Symptomatik von Schlaganfällen informiert werden mit dem Ziel, die ASS-Therapie sofort selbst einzuleiten.

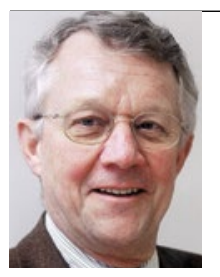

Prof. Dr. med. Heinrich Holzgreve Kardiologische Praxis, München 